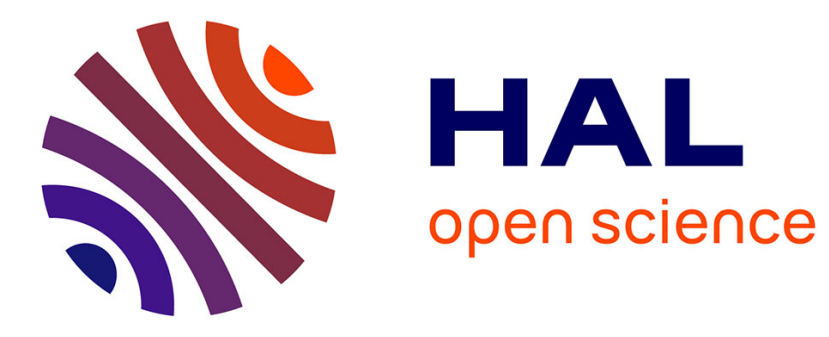

\title{
Heavy-Chain Deposition Disease
}

Pierre Aucouturier, Ahmed A Khamlichi, Guy Touchard, Eve Justrabo, Michel Cogné, Bruno Chauffert, François Martin, Jean-Louis Preud'Homme

\section{To cite this version:}

Pierre Aucouturier, Ahmed A Khamlichi, Guy Touchard, Eve Justrabo, Michel Cogné, et al.. HeavyChain Deposition Disease. New England Journal of Medicine, 1993, 329 (19), pp.1389 - 1393. 10.1056/NEJM199311043291905 . inserm-01876787

\section{HAL Id: inserm-01876787 https://www.hal.inserm.fr/inserm-01876787}

Submitted on 18 Sep 2018

HAL is a multi-disciplinary open access archive for the deposit and dissemination of scientific research documents, whether they are published or not. The documents may come from teaching and research institutions in France or abroad, or from public or private research centers.
L'archive ouverte pluridisciplinaire HAL, est destinée au dépôt et à la diffusion de documents scientifiques de niveau recherche, publiés ou non, émanant des établissements d'enseignement et de recherche français ou étrangers, des laboratoires publics ou privés. 


\section{BRIEF REPORT: HEAVY-CHAIN DEPOSITION DISEASE}

Pierre Aucouturier, Ph.D., Ahmed A. Khamlichi, Guy Touchard, M.D., Eve Justrabo, M.D., Michel Cogne, M.D., Ph.D.,

Bruno Ghauffert, M.D., François Martin, M.D., and Jean-Louis Preud'homme, M.D., Ph.D.

TIGHT-CHAIN amyloidosis and light-chain deposition disease are closely related processes characterized by tissue deposition of organized (fibrillar) or nonorganized material related to monoclonal immunoglobulin light chains. Both conditions can occur in patients with immunoproliferative disorders. The clinical manifestations of light-chain deposition disease result from multivisceral involvement and are heterogeneous. Rapidly progressive renal failure or the nephrotic syndrome is the most common manifestation, but heart failure, arrhythmia, liver involvement (peliosis), and neurologic disorders may also be present. These findings may be caused by structural abnormalities or unusual behavior of deposited light chains. In particular, pathogenic light chains are characterized by unusual sizes, glycosylation, variable-region subgroups, exposed hydrophobic amino acid residues, or the propensity to polymerize or aggregate. ${ }^{1}$ Soon after the first description of light-chain deposition disease ${ }^{2}$ it became apparent that heavy chains that are monoclonal in origin may be found together with light chains in the tissue of some patients. ${ }^{3}$

Eulitz et al. have described a patient with systemic heavy-chain amyloidosis in whom the amyloid component was a short IgG heavy $(\gamma)$ chain alone. ${ }^{4}$ The shortened heavy chain belonged to the $\gamma 1$ subclass and contained a normal variable domain directly linked to the third constant domain. We now describe two patients with a disorder that resembled light-chain deposition disease both clinically and pathologically in whom the kidney deposits contained short heavy chains but no detectable light chains. Unlike the deposits associated with systemic heavy-chain amyloidosis, these deposits had a nonfibrillar structure and did not stain with Congo red. The sequence of the truncated heavy chain from one patient was strikingly sim-

From the Laboratory of Immunology and Molecular Interactions (Centre National de la Recherche Scientifique Associated Research Unit 1172), University Hospital and Faculty of Sciences, Poitiers (P.A., A.A.K., M.C., J.-L.P.); the Department of Nephrology, University Hospital, Poitiers (G.T.); and the Department of Pathology (E.J.) and the Human and Experimental Digestive Cancer Unit (Institut National de la Santé et de la Recherche Médicale Unit 252) (B.C., F.M.), University Hospital, Dijon - all in France. Address reprint requests to Dr. Aucouturier at the Centre National de la Recherche Scientifique, Unité de Recherche Associée 1172, Centre Hospitalier Universitaire, B.P. 577, F-86021 Poitiers, France.

Supported in part by grants from the Institut National de la Santé et de la Recherche Médicale (CRE930602) and the Association pour la Recherche sur le Cancer (6044) and by a fellowship from the Ligue Nationale Contre le Cancer (to Mr. Khamlichi). ilar to that of the protein found in the patient with systemic heavy-chain amyloidosis. ${ }^{4}$ We believe that this condition, characterized by nonamyloid deposits of heavy chains, is a specific entity - namely, heavychain deposition disease.

\section{Methods}

\section{Patients}

Patient 1, a 53-year-old woman, was referred because of hypertension, leg edema, exertional dyspnea, and anemia of five months' duration. Her urinary protein excretion was $4.4 \mathrm{~g}$ per 24 hours. Her serum total protein concentration was $47 \mathrm{~g}$ per liter, with $27 \mathrm{~g}$ of albumin per liter and $4 \mathrm{~g}$ of gamma globulin per liter (normal, 8 to 16). Thin-layer agarose electrophoresis revealed peaks of beta- 2 and gamma globulin. The serum creatinine concentration was 1.5 mg per deciliter (133 $\mu \mathrm{mol}$ per liter). Bone marrow aspiration showed 8 percent plasma cells, and the results of a bone marrow biopsy were consistent with a diagnosis of multiple myeloma, with infiltration of plasma cells that stained with fluorescein-conjugated anti- $\gamma$-heavy-chain and anti- $\lambda$-light-chain antibodies by direct immunofluorescence. No cells containing $\boldsymbol{\kappa}$ light chains were detected. The patient was treated with melphalan, prednisone, albumin, and antihypertensive drugs. Nine months later, she was asymptomatic, but her bone marrow was hypoplastic, with minimal plasma-cell infiltration ( 1 to 2 percent), and she had persistent proteinuria ( 5 to $7 \mathrm{~g}$ per 24 hours) and hypoproteinemia.

Patient 2, a 59-year old woman referred because she had hypertension and the nephrotic syndrome, had a long history of autoimmune disorders, including Graves' hyperthyroidism followed by Hashimoto's thyroiditis with a goiter and persistently high serum concentrations of antithyroid, antinuclear, and antigastric parietalcell antibodies. She also had chronic thrombocytopenia, which had been treated unsuccessfully with prednisolone and cyclophosphamide and then with vincristine and danazol, and diabetes mellitus that was controlled by diet. Her 24-hour urinary protein excretion was 3 to $18 \mathrm{~g}$. The serum total protein concentration was $52 \mathrm{~g}$ per liter, with $26 \mathrm{~g}$ of albumin per liter and $4 \mathrm{~g}$ of gamma globulin per liter. The patient was treated initially with intravenous immune globulin in a dose of $30 \mathrm{~g}$ per day for five days. A renal biopsy was performed and repeated (after platelet infusions) twice: 2 months later, to rule out the possibility that the infused immune globulin was deposited in glomeruli; and 15 months later because her serum creatinine concentration had increased from 1.6 to $7.1 \mathrm{mg}$ per deciliter (140 to $630 \mu \mathrm{mol}$ per liter). A liver biopsy was performed because of an elevated serum alkaline phosphatase concentration. Monoclonal-plasma-cell proliferation was not detected by skeletal $\mathrm{x}$-ray survey, bone marrow aspiration and biopsy, thyroidectomy, or cytoplasmic immunofluorescence studies of bone marrow and thyroid cells with the use of antibodies to immunoglobulin heavy chains (including IgG-subclass-specific antibodies) and light chains. Treatment with chlorambucil, methylprednisolone, and plasma exchanges resulted in transient improvement; subsequent treatment with melphalan and prednisolone had no effect.

\section{Pathological Studies}

Fragments of tissue specimens (kidney and bone marrow from both patients and liver and thyroid from Patient 2) were processed for light, electron, and immunofluorescence microscopy with the use of fluorescein-labeled antibodies specific for immunoglobulin heavy and light chains and for C1q, C3, C4, fibrinogen, and albumin and for indirect assays with the monoclonal antibodies described below.

\section{Immunochemical Studies}

Serum and concentrated urine samples from both patients were studied by high-resolution electrophoresis, immunoelectrophoresis, 
and Western blot analysis. ${ }^{5}$ The immunologic studies were performed with monoclonal antibodies specific for $\kappa$ light chains, $\lambda$ light chains, heavy-chain constant domains, and IgG subclasses. The antigen-antibody reactions were detected with alkaline phosphatase-conjugated antimouse IgG antibodies and were visualized with nitroblue tetrazolium and bromochloro-indolyl phosphate.

The abnormal (shortened) IgG from Patient 1 was partially purified by diethylaminoethyl and Sephadex G-150 superfine chromatography and analyzed by sodium dodecyl sulfate-polyacrylamidegel electrophoresis followed by Western blotting. The size of the native molecule was evaluated on calibrated Sephadex G-100 and G-150 superfine columns.

\section{Study of Messenger RNA in Patient 1}

Single-stranded complementary DNA (cDNA) was synthesized from bone marrow messenger RNA from Patient 1, with reverse transcriptase and random hexadeoxynucleotides used as primers. A series of polymerase chain reactions was performed with the cDNA as a template, a $3^{\prime}$ primer (5'CGAGAGCGCGGGGAGCGGGG3') complementary to a noncoding sequence downstream from the third heavy-chain constant $(\mathrm{CH} 3)$ exon that is identical in the four IgG subclasses, and six different $5^{\prime}$ primers that were consensus sequences of every subgroup leader of the variable region (VH) ${ }^{6,7}$ Two further independent amplifications were performed with the same $3^{\prime}$ primer and the $5^{\prime}$ primer corresponding to the third subgroup $\left(\mathrm{VH}_{\mathrm{III}}\right)$ leader exon (5'ATGGAGTTTGGGCTGAGC3'). The amplification products and restriction fragments were independently cloned into mpl8 and mpl9 vectors, and both strands were sequenced. ${ }^{8}$

\section{Results}

\section{Histopathological Studies}

The microscopical appearance of the renal-biopsy specimens from the two patients was similar, and the renal, bone marrow, and thyroid specimens from $\mathrm{Pa}$ tient 2 had many similarities (Fig. 1). Light microscopy showed nodular glomerulosclerosis but no fluorescence after staining with thioflavine $\mathrm{T}$ and no green birefringence under polarized light after staining with Congo red. After silver methenamine impregnation, the glomerular nodules were heterogeneously argyrophilic and sometimes laminated. Renal tubular-cell basement membranes were thickened by a refractile ribbonlike material that was positive on periodic acid-Schiff staining. Fibrinoid deposits were present in mesangial nodules and around renal tubules in $\mathrm{Pa}$ tient 2. No arteriolar hyaline deposits or exudative lesions, such as fibrinoid caps, were seen. Material positive on periodic acid-Schiff staining was present around smooth-muscle cells of the arterial and arteriolar walls in the kidney and bone marrow specimens from Patient 2.

Immunofluorescence with polyclonal antiserum showed staining only with the anti- $\gamma$-heavy-chain conjugate in the mesangial areas; along the glomerular-capillary, capsular, and tubular basement membranes in both patients; and around vascular smoothmuscle cells in Patient 2, in whom there were also $\boldsymbol{\gamma}$-heavy-chain deposits in Disse's spaces in the liver and around thyroid follicles. The absence of detectable light chains was confirmed with the use of mono- clonal antibodies. The deposited heavy chains lacked epitopes in the first and second constant domains in Patient 1 and in the first constant domain in Patient 2 (Table 1); the chains belonged to a single IgG subclass $(\gamma 4)$ in Patient 2.

Electron microscopy showed deposits very similar to those reported in light-chain deposition disease. The enlarged nodular mesangial areas in the kidneys contained finely granular basement-membrane-like material. In Patient 2, the same nonorganized granular deposits were present along the internal part of glomerular basement membranes and along tubular basement membranes, as well as around vascular smooth-muscle cells. The lamina densa of the glomerular-capillary walls was not thickened. The results of the three kidney biopsies performed in Patient 2 were identical.

\section{Immunochemical and Sequencing Studies of Serum and Urine}

The serum (five samples) and concentrated urine (two samples) from Patient 2 contained small amounts of several monoclonal immunoglobulins, which were probably related to long-term immunosuppressive therapy. ${ }^{9}$ The patient's IgG4 appeared to be polyclonal, and no short heavy chain could be found by Western blotting after sodium dodecyl sulfate-polyacrylamide-gel electrophoresis. In both patients, tests for cryoglobulins were negative.

The serum and urine from Patient 1 contained two monoclonal forms of $\mathrm{IgG}$, one with gamma globulin and the other with beta-2 globulin mobility; the latter lacked heavy-chain epitopes by immunoelectrophoresis. A $\lambda$-chain Bence Jones protein was detected in the patient's urine. The slow-migrating IgG was an apparently normal IgG1, whereas the fast-migrating IgG was unreactive with antibodies to the first and second constant domains (Table 1). The native protein had an apparent molecular weight of 94,000. This finding and the results of gel electrophoresis (Fig. 2) indicated that this short IgG was made up of two truncated ( $24 \mathrm{kd}$ ) heavy chains noncovalently linked to a covalent dimer of normal-sized $\lambda$ light chains.

A polymerase-chain-reaction product of about 0.8 $\mathrm{kb}$ was consistently obtained with the upstream primer corresponding to the $\mathrm{VH}_{\text {III }}$ leader sequence. The sequences of clones from three independent amplifications were identical. Each clone contained a normally rearranged variable exon made up of $\mathrm{VH}_{\mathrm{III}}, \mathrm{D}_{\mathrm{H}}$, and $\mathrm{J}_{\mathrm{H}}$ segments and directly joined to a normal heavychain $\mathrm{CH} 3$ exon. Comparison of the deduced sequence with the sequences of $82 \mathrm{VH}_{\mathrm{III}}$ regions described elsewhere ${ }^{10}$ showed that eight amino acids present in this protein had not been reported at the corresponding positions in the other sequences. In particular, highly conserved residues in the framework regions were mutated; tryptophan 47, for example, 


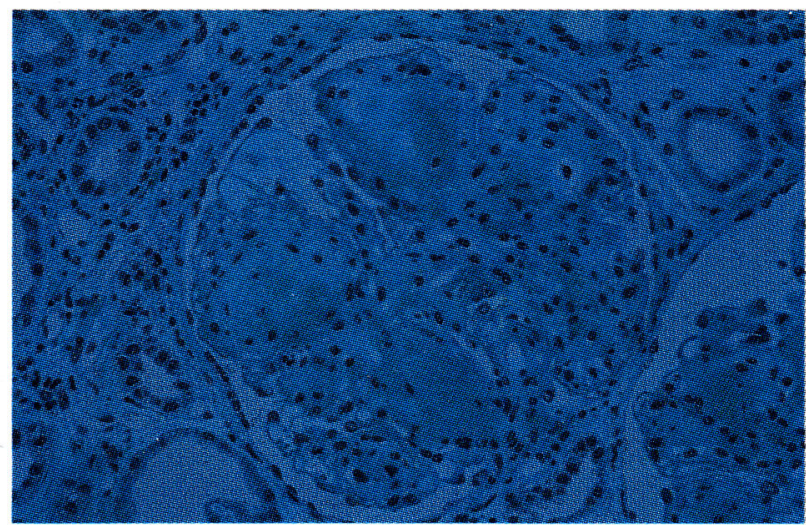

A

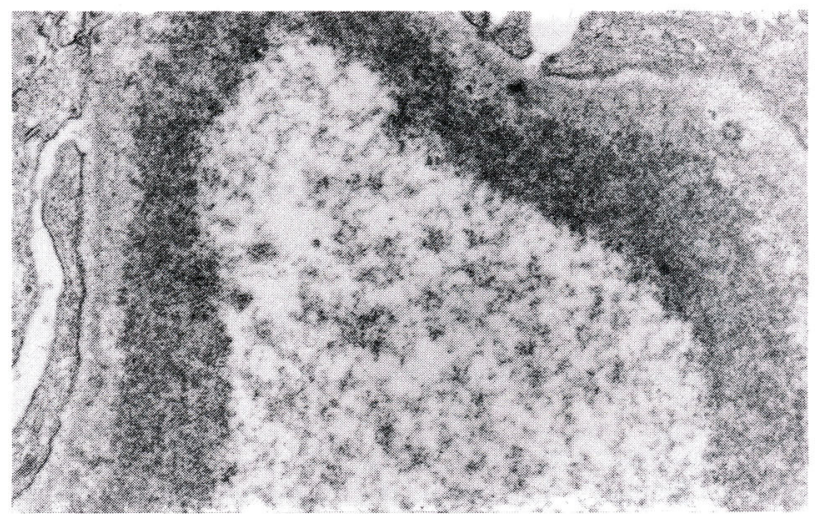

C



$\mathrm{E}$

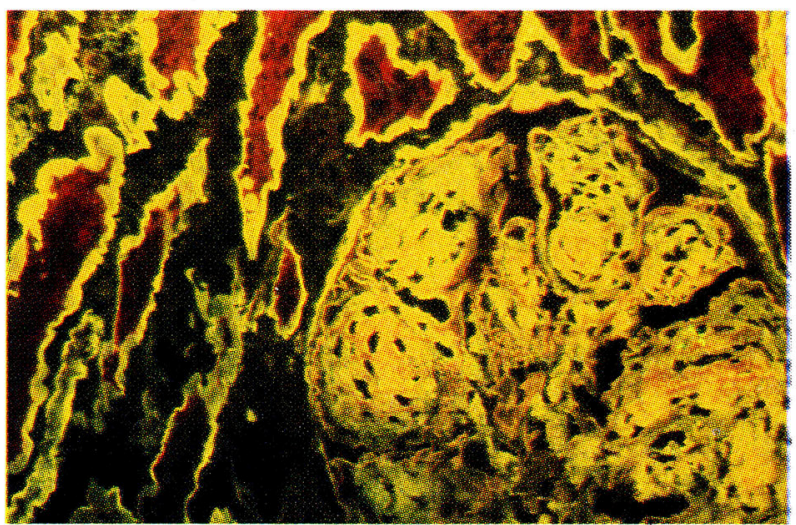

B
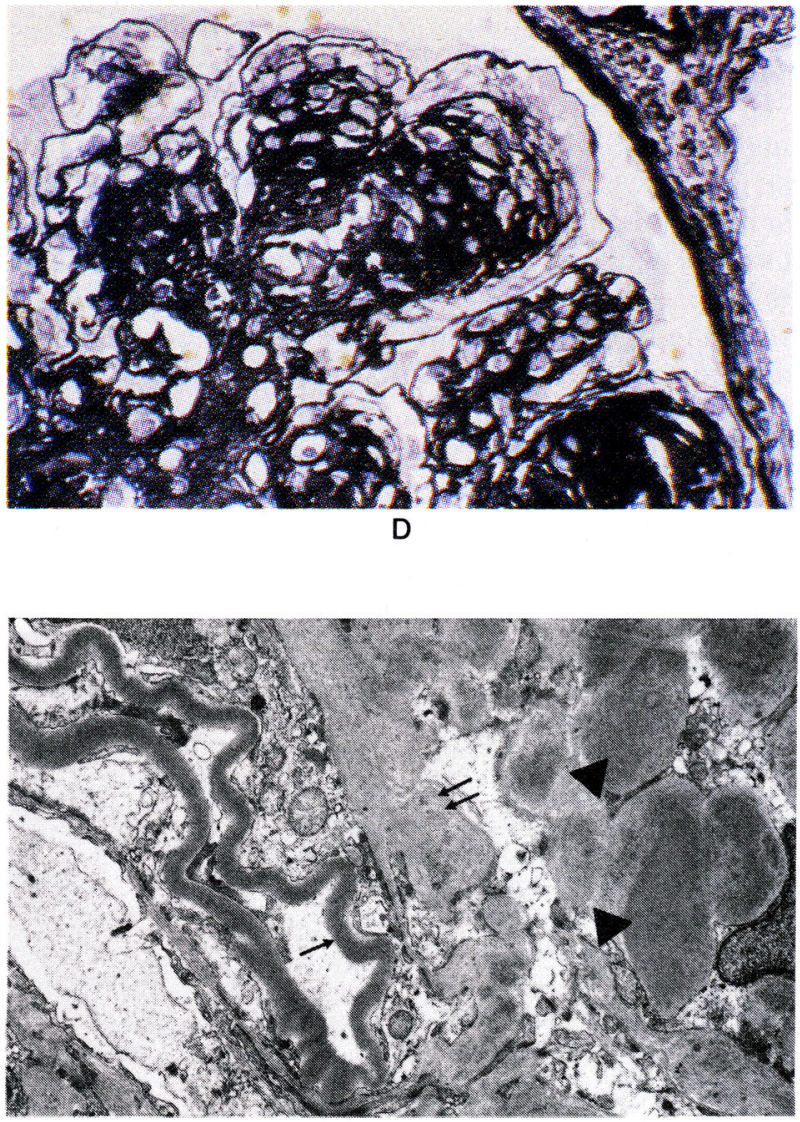

Figure 1. Renal-Biopsy Findings in Patients 1 (Panels A, B, and C) and 2 (Panels D, E, and F) with Heavy-Chain Deposition Disease. In Panel A a light-microscopical section stained with Masson's trichrome shows nodular glomerulosclerosis with enlarged glomerularcapillary tuft $(\times 410)$. In Panel B a section stained with anti- $\gamma$-heavy-chain antibodies conjugated with fluorescein shows deposition of immunoglobulin heavy chain along the tubular, capsular, and glomerular basement membranes and in the mesangial nodules $(\times 410)$. In Panel $\mathrm{C}$ an electron-microscopical section shows finely granular osmiophilic deposits in the lamina rara interna and in the internal part of the lamina densa of a glomerular-capillary loop $(\times 25,000)$. In Panel D a light-microscopical section with Marinozzi's silver impregnation shows laminated mesangial nodules with microaneurysmal dilatation of the lumens of peripheral-glomerular-capillary loops $(\times 510)$. In Panel $E$ a section stained with anti- $\gamma$-heavy-chain antibodies conjugated with fluorescein shows deposition of immunoglobulin heavy chain along the basement membranes and around smooth-muscle cells in an arterial wall $(\times 510)$. In Panel $F$ an electron-microscopical section shows deposition of osmiophilic material along the glomerular-capillary basement membrane (arrow) and in the mesangium (double arrow) and glomerular osmiophilic deposits in the mesangium (arrowheads) mixed with collagen microfibrils (not shown) $(\times 3400)$. 
was replaced by a cysteine. The full deduced sequence is available elsewhere.*

\section{Discussion}

The two patients we studied have a disorder that is clinically and pathologically indistinguishable from light-chain deposition disease, except by immunofluorescence studies, and that clearly differs from amyloidosis. We believe them to have heavy-chain deposition disease, because the tissue deposits in both patients strongly stained for heavy chains. Light-chain determinants were undetectable by immunofluorescence with potent polyclonal and monoclonal reagents. Both patients presented with renal disease, but the process is probably more widespread, as evidenced in Patiént 2. Diabetic nephropathy was ruled out by the results of light and immunofluorescence microscopy, and amyloidosis was ruled out by electron microscopy.

In Patient 1 a heavy-chain cDNA lacking the $\mathrm{CH}$, hinge, and $\mathrm{CH} 2$ domains was amplified from bone marrow RNA. The corresponding protein was the single immunoglobulin component in the renal deposits. It was noncovalently linked to $\lambda$ light-chain dimers in the serum and urine. These findings are similar to those reported in a patient with systemic heavy-chain amyloidosis, ${ }^{4}$ whose abnormal protein also belonged to the $\mathrm{VH}_{\mathrm{III}}$ subgroup and $\gamma \mathrm{l}$ subclass; however, its variable region was strikingly different, and it belonged to a different allotype. The primary structure

*See NAPS document no. 05061 for one page of supplementary material. Order from NAPS c/o Microfiche Publications, P.O. Box 3513, Grand Central Station, New York, NY 10163-3513. Remit in advance (in U.S. funds only) $\$ 7.75$ for photocopies or $\$ 4$ for microfiche. Outside the U.S. and Canada, add postage of $\$ 4.50$ ( $\$ 1.75$ for microfiche postage). There is a $\$ 15$ invoicing charge for all orders filled before payment.

Figure 2. Immunoblot Analysis after Sodium Dodecyl Sulfate-Polyacrylamide-Gel Electrophoresis of Protein Partially Purified from the Serum of Patient $1(P)$ and from a Patient with a Normal-Sized Myeloma IgG (N) under Reducing and Nonreducing Conditions.

The following monoclonal antibodies were used: 1 , anti- $\lambda$-light-chain antibody (HP6054); 2, anti- $\gamma$-heavy-chain antibody reactive with the $\mathrm{CH} 3$ domain (clone HP6017); and 3 , anti- $\gamma$-heavy-chain antibody reactive with the $\mathrm{CH} 2$ domain (HP6018).

Table 1. Monoclonal-Antibody Reactivity of Abnormal IgG in Two Patients with Heavy-Chain Deposition Disease.*

\begin{tabular}{|c|c|c|c|c|}
\hline \multirow[t]{2}{*}{ ANTIBODY } & \multirow[t]{2}{*}{ SPECIFICITY } & \multicolumn{2}{|c|}{ Patient 1} & \multirow[t]{2}{*}{$\begin{array}{c}\text { Patient } 2 \\
\text { Kidney } \\
\text { Deposits }\end{array}$} \\
\hline & & $\begin{array}{c}\text { SERUM } \\
\text { PROTEIN }\end{array}$ & $\begin{array}{c}\text { KIDNEY } \\
\text { DEPOSITS }\end{array}$ & \\
\hline HP6053 & $\kappa$ & - & - & - \\
\hline HP6054 & $\lambda$ & + & - & - \\
\hline TM15 & $\gamma \mathrm{CH} 1$ & - & NT & - \\
\hline HP6044 & $\gamma \mathrm{CH} 1$ & - & - & - \\
\hline G7C & $\gamma \mathrm{CH} 2$ & - & NT & + \\
\hline GG7 & $\gamma \mathrm{Fc} \dagger$ & - & - & + \\
\hline HP6018 & $\gamma$ Fct & - & NT & NT \\
\hline $1 \mathrm{~A} 1$ & $\gamma 1-3$ CH3 & + & NT & - \\
\hline HP6017 & $\gamma \mathrm{Fc} \dagger$ & + & + & + \\
\hline NL16 & $\gamma 1 \mathrm{CH} 2$ & - & NT & - \\
\hline GOM2 & $\gamma 2 \mathrm{CH} 2$ & - & NT & - \\
\hline HP6014 & $\gamma 2 \mathrm{CH} 1$ & - & NT & - \\
\hline ZG4 & $\gamma 3$ hinge region & - & NT & - \\
\hline RJ4 & $\gamma 4 \mathrm{CH} 3$ & - & NT & + \\
\hline
\end{tabular}

$*_{\kappa}$ denotes $\kappa$ light chains; $\lambda, \lambda$ light chains; $\gamma \mathrm{CH} 1$, the first constan domain of IgG heavy chain; $\gamma \mathrm{CH} 2$, the second constant domain; $\gamma \mathrm{CH} 3$, the third constant domain; and NT, not tested.

$\dagger$ The precise specificity of this antibody was not known, but it was known to react with the $\mathrm{Fc}$ fragment of IgG (which encompasses the $\mathrm{CH} 2$ and $\mathrm{CH} 3$ domains). Given its reactivity in Patient 1 , it was necessarily reactive with an epitope of the CH2 (GG7 and HP6018) or CH3 (HP6017) domain.

$\ddagger$ Reactive with an epitope shared by $\gamma 1, \gamma 2$, and $\gamma 3$ heavy chains.

of the variable region of the protein in Patient 1 had unusual features that might play a part in tissue deposition.

The short heavy chains in our patients and in the patient with heavy-chain amyloidosis lacked the $\mathrm{CH} 1$ domain. The domain is present in the heavy chains of almost all patients with heavy-chain disease, a disorder in which there is no kidney disease and no depo-

\section{Reducing}

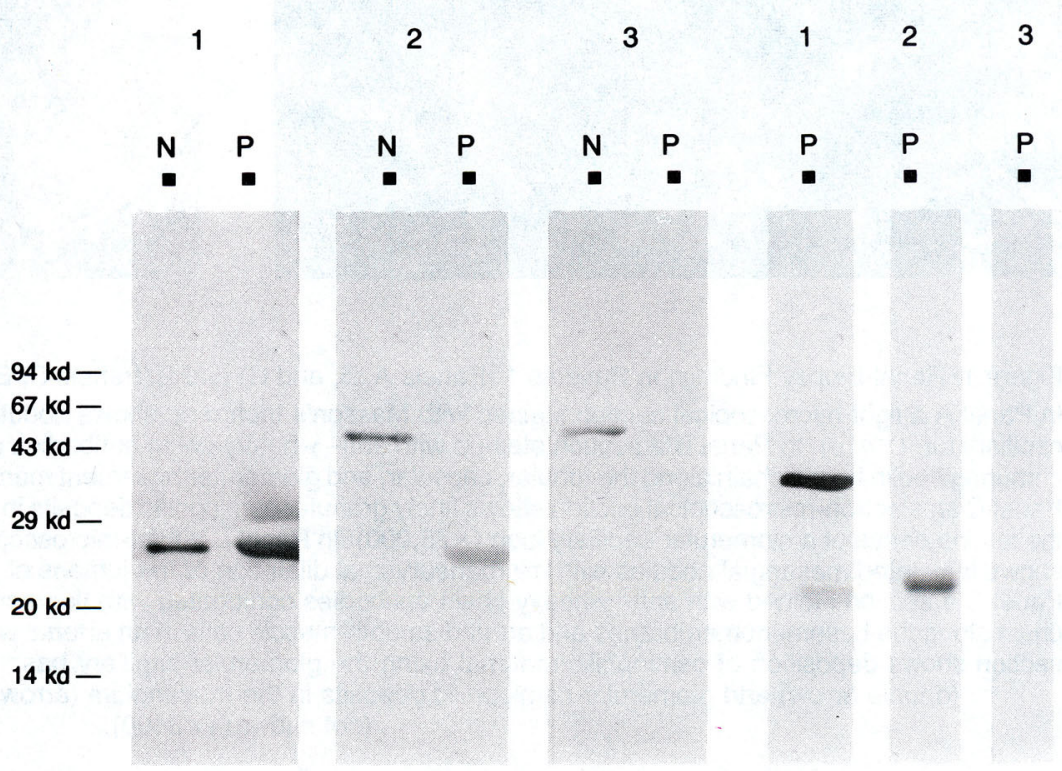


sition of heavy chains. ${ }^{1}$ The absence of the $\mathrm{CH}$ l domain and the unusual structure of the protein in $\mathrm{Pa}$ tient 1 suggest that the variable region has a role in tissue deposition.

No clinical feature distinguishes light-chain deposition disease from heavy-chain deposition disease. Both conditions may be associated with various immunoproliferative disorders or found in the absence of an overt malignant process. However, the predominant disease in patients with either light- or heavy-chain deposition is myeloma, whereas myeloma is extremely rare in patients with heavy-chain disease. Hence, the finding of symptoms (especially renal) known to be associated with light-chain deposition, especially in patients with myeloma, should lead to the use of antiheavy-chain antibodies in biopsy studies.

We are indebted to Drs. George Carlone (Centers for Disease Control and Prevention, Atlanta) and Margaret Goodall (Recognition Sciences, Birmingham, United Kingdom) for the gift of monoclonal antibodies, to Mrs. Françoise Buisson for expert editorial assistance, and to Drs. Joel Buxbaum (New York) and Jean-Claude Brouet (Paris) for their critical reading of the manuscript.

\section{REFERENCES}

1. Cogné M, Silvain C, Khamlichi AA, Preud'homme JL. Structurally abnormal immunoglobulins in human immunoproliferative disorders. Blood 1992;79:2181-95.

2. Randall RE, Williamson WC Jr, Mullinax F, Tung MY, Still WJS. Manifestations of systemic light chain deposition. Am J Med 1976;60:293-9.

3. Preud'homme JL, Morel-Maroger L, Brouet JC, Mihaesco E, Mery JP, Seligmann M. Synthesis of abnormal heavy and light chains in multiple myeloma with visceral deposition of monoclonal immunoglobulin. Clin Exp Immunol 1980;42:545-53.

4. Eulitz M, Weiss DT, Solomon A. Immunoglobulin heavy-chain-associated amyloidosis. Proc Natl Acad Sci U S A 1990;87:6542-6.

5. Briault S, Courtois-Capella M, Duarte F, Aucouturier P, Preud'homme JL. Isotypy of serum monoclonal immunoglobulins in human immunodeficiency virus-infected adults. Clin Exp Immunol 1988;74:182-4.

6. Kelly PJ, Pascual V, Capra JD, Lipsky PE. Anti-CD3-stimulated T cells induce the production of multiple Ig $\mathrm{H}$ chain isotypes by individual human peripheral B lymphocytes. J Immunol 1992;148:1294-301.

7. Campbell MJ, Zelenetz AD, Levy S, Levy R. Use of family specific leader region primers for PCR amplification of the human heavy chain variable region gene repertoire. Mol Immunol 1992;29:193-203.

8. Sanger F, Nicklen S, Coulson AR. DNA sequencing with chain-terminating inhibitors. Proc Natl Acad Sci U S A 1977;74:5463-7.

9. Radl J. Age-related monoclonal gammapathies: clinical lessons from the aging C57BL mouse. Immunol Today 1990;11:234-6.

10. Human heavy chains subgroup III. In: Kabat EA, Wu TT, Perry HM, Gottesman KS, Foeller C. Sequences of proteins of immunological interest. 5th ed. Vol. 1. Bethesda, Md.: National Institutes of Health, 1991:324-38. (DHHS publication no. (NIH) 91-3242.) 